Check for updates

Cite this: Metallomics, 2018, 10, 1180

Received 26th June 2018, Accepted 24th July 2018 DOI: $10.1039 / c 8 m+00159 f$

rsc.li/metallomics

\title{
Influence of zinc on glycosaminoglycan neutralisation during coagulation
}

\author{
Amélie I. S. Sobczak, (D) Samantha J. Pitt (D) and Alan J. Stewart (D) *
}

\begin{abstract}
Heparan sulfate (HS), dermatan sulfate (DS) and heparin are glycosaminoglycans (GAGs) that serve as key natural and pharmacological anticoagulants. During normal clotting such agents require to be inactivated or neutralised. Several proteins have been reported to facilitate their neutralisation, which reside in platelet $\alpha$-granules and are released following platelet activation. These include histidine-rich-glycoprotein (HRG), fibrinogen and high-molecular-weight kininogen (HMWK). Zinc ions $\left(\mathrm{Zn}^{2+}\right)$ are also present in $\alpha$-granules at a high concentration and participate in the propagation of coagulation by influencing the binding of neutralising proteins to GAGs. $\mathrm{Zn}^{2+}$ in many cases increases the affinity of these proteins to GAGs, and is thus an important regulator of GAG neutralisation and haemostasis. Binding of $\mathrm{Zn}^{2+}$ to HRG, HMWK and fibrinogen is mediated predominantly through coordination to histidine residues but the mechanisms by which $\mathrm{Zn}^{2+}$ increases the affinity of the proteins for GAGs are not yet completely clear. Here we will review current knowledge of how $\mathrm{Zn}^{2+}$ binds to and influences the neutralisation of GAGs and describe the importance of this process in both normal and pathogenic clotting.
\end{abstract}

\section{Introduction}

Glycosaminoglycans (GAGs) including heparin sulfate (HS), dermatan sulfate (DS) and heparins are key molecules involved in several biological processes, including coagulation where they play an important anticoagulant role. ${ }^{1} \mathrm{HS}$ is mostly synthesised by endothelial cells, where it lines the endothelium and participates in its intrinsic anticoagulant properties. ${ }^{2}$ DS is mostly synthesised in the sub-endothelium and is exposed to plasma proteins during injury. ${ }^{3}$ Heparins are synthesised by mast cells and may also be secreted following tissue injury, ${ }^{4,5}$ however, this has been disputed by some. ${ }^{6-8}$ The main relevance of heparins are in clinical settings, where they and heparin-based drugs are important agents used in the clinical treatment of coagulatory disorders. ${ }^{9}$ As GAGs are physiologically found in a variety of sizes, heparin drugs are administered clinically as unfractionated heparin (UFH), which have not been cleaved or separated by size or as low molecular weight heparin (LMWH), which are generally $<8000 \mathrm{Da}^{10}$ All GAGs exercise their anticoagulant activity through their binding to serpins. ${ }^{1}$ The main partners for HS and heparin are antithrombin (AT) and heparin cofactor II (HCII) while DS can only bind to HCII. ${ }^{1}$ When bound together, the GAGs can change the conformation of the reactive centre loop of the serpin to increase the inhibitory activity of the molecule. ${ }^{11}$ During normal

School of Medicine, University of St Andrews, Medical and Biological Sciences Building, St Andrews, Fife, UK. E-mail: ajs21@st-andrews.ac.uk;

Fax: +44 (0)1334 463482; Tel: +44 (0)1334 463546 coagulation, when clotting is required, anticoagulant GAGs are neutralised by several proteins, including histidine-richglycoproteins (HRG), high-molecular-weight kininogen (HMWK) and fibrinogen. ${ }^{10,12}$

After iron, zinc is the most abundant transition metal in the human body. Zinc is an important element in the body, playing key structural and catalytic roles as well as functioning as an extracellular and intracellular signalling molecule. Ionic zinc $\left(\mathrm{Zn}^{2+}\right)$ is essential for physiological processes such as cell replication, tissue growth, immune functioning and coagulation. ${ }^{13-15}$ The importance of $\mathrm{Zn}^{2+}$ is best illustrated by the cases of zinc deficiency, which is defined as having a total plasma zinc concentration below $0.7 \mathrm{mg} \mathrm{L}^{-1}$ (normal range is $\left.0.8-1.0 \mathrm{mg} \mathrm{L} \mathrm{L}^{-1}\right) .{ }^{16-18}$ Zinc deficiency is associated with coagulatory abnormalities including a reduced ability for platelets to aggregate and longer bleeding times, which in most cases can be quickly corrected by zinc supplementation without secondary effects. ${ }^{16-18}$ In addition to the resting plasma $\mathrm{Zn}^{2+}$ level, during coagulation platelets release $\mathrm{Zn}^{2+}$ stored in their $\alpha$-granules, thus initiating a signalling process. ${ }^{19-21}$ During this process $\mathrm{Zn}^{2+}$ acts to propagate several anticoagulation pathways as well as both pro- and anti-fibrinolytic pathways. ${ }^{13}$ In addition to $\mathrm{Zn}^{2+}$, platelet $\alpha$-granules also release numerous proteins that impact on coagulation, among which are HRG, HMWK and fibrinogen. ${ }^{10,22}$ These proteins have both the ability to bind $\mathrm{Zn}^{2+}$ and to bind and neutralise anticoagulant GAGs. ${ }^{23-30}$ The mechanisms and impact by which $\mathrm{Zn}^{2+}$ influences GAG binding and neutralisation by these proteins is reviewed here. 


\section{$\mathrm{Zn}^{2+}$ repartition in plasma}

Despite its requirement for various physiological processes, $\mathrm{Zn}^{2+}$ is toxic at mid-high micromolar levels, ${ }^{31,32}$ therefore its free/labile concentration is tightly regulated. The total concentration of $\mathrm{Zn}^{2+}$ in the plasma is approximately $20 \mu \mathrm{M} .^{33}$ Those ions are mostly bound to serum albumin $(75 \%$ of the total $\mathrm{Zn}^{2+}$ concentration in the body, i.e. around $\left.15 \mu \mathrm{M}\right){ }^{33}$ The remaining $\mathrm{Zn}^{2+}$ (around 5-6 $\mu \mathrm{M}$ ) is bound to other proteins such as $\alpha_{2}$-macroglobulin. ${ }^{15,34}$ This fraction is regarded as nonexchangeable as the binding is very tight. ${ }^{15,34}$ The remaining $\mathrm{Zn}^{2+}$ is bound to small ligands and is considered "free" or "labile" because those ligands can easily be exchanged for proteins or other ligands (more easily than when $\mathrm{Zn}^{2+}$ is bound to serum albumin). ${ }^{15,34}$ The free $\mathrm{Zn}^{2+}$ concentration in plasma is generally thought to be in the micromolar range, between 0.5 to $1 \mu \mathrm{M} .^{15,34}$

The proportion of free/labile $\mathrm{Zn}^{2+}$ in plasma is dynamic (Fig. 1). For example, during coagulation, $\mathrm{Zn}^{2+}$ is released from platelets. ${ }^{35,36}$ Healthy platelets accumulate around $35 \mathrm{~g} \mathrm{~L}^{-1}$ of $\mathrm{Zn}^{2+}$ that they sequester into two pools, the cytoplasm (around $60 \%$ that is used to regulate platelet function) $)^{21,37}$ and the $\alpha$-granules (around 40\%). ${ }^{21}$ Variations of the total amount of $\mathrm{Zn}^{2+}$ present in the plasma affect the quantity present in the platelets, as well as the distribution of the two pools. ${ }^{37}$ There is still some uncertainty as to how $\mathrm{Zn}^{2+}$ is incorporated into the platelets. Some $\mathrm{Zn}^{2+}$ may be incorporated when the $\mathrm{Zn}^{2+}$-bound fibrinogen-coagulation factor XIII $\left(\mathrm{a}_{2}\right)$ complex enters the platelet through binding to fibrinogen receptors. ${ }^{37}$ However the main mechanism for $\mathrm{Zn}^{2+}$ entry into platelets is likely to be through $\mathrm{Zn}^{2+}$ transporters (as reviewed by Taylor and Pugh); ${ }^{38}$ the exact mechanism however remains to be elucidated. When platelets are activated, up to half of the $\alpha$-granule $\mathrm{Zn}^{2+}$ pool is released. ${ }^{35,36}$ This action has been reported to increase the labile/free plasma $\mathrm{Zn}^{2+}$ concentration to $7-10 \mu \mathrm{M}$ in the proximities of activated platelets. ${ }^{35,36}$ The resultant increase in $\mathrm{Zn}^{2+}$ concentration can then facilitate its binding to coagulatory proteins and in-turn alter their affinity for other proteins or ligands to influence the coagulation process. ${ }^{19,20}$ Platelets are not the only cells in the blood that store $\mathrm{Zn}^{2+}$. Indeed, neutrophils, lymphocytes and erythrocytes all contain $\mathrm{Zn}^{2+}$ (reported levels of total zinc are $105 \mu \mathrm{g} / 1 \times 10^{10}$ cells, $116 \mu \mathrm{g} / 1 \times 10^{10}$ cells and $41 \mu \mathrm{g} \mathrm{g}{ }^{-1}$ haemoglobin, respectively) ${ }^{39}$ and may therefore release $\mathrm{Zn}^{2+}$ under certain circumstances in a manner similar to platelets (such as at sites of injury, although this has yet to be confirmed). In addition, the epithelium contains around $60 \mu \mathrm{g} \mathrm{Zn}{ }^{2+} / \mathrm{g}$ of dry weight, ${ }^{40}$ and epithelial cells release some of this when damaged (the exact amount is not known). ${ }^{41}$

\section{Relevance of $\mathrm{Zn}^{2+}$ in coagulation control}

For a long time, the role of $\mathrm{Zn}^{2+}$ in coagulation had been ignored and was likely often masked by the use of citrate as an anticoagulant during blood collection (with citrate forming complexes with metallic cations). However, in more recent years, the importance of $\mathrm{Zn}^{2+}$ in coagulation and regulation of platelet function has started to emerge. ${ }^{13,38,42}$ A variety of blood proteins involved in coagulatory processes have been identified as $\mathrm{Zn}^{2+}$-binding proteins. In many cases the ability to bind $\mathrm{Zn}^{2+}$ has the potential to influence their activities and impact

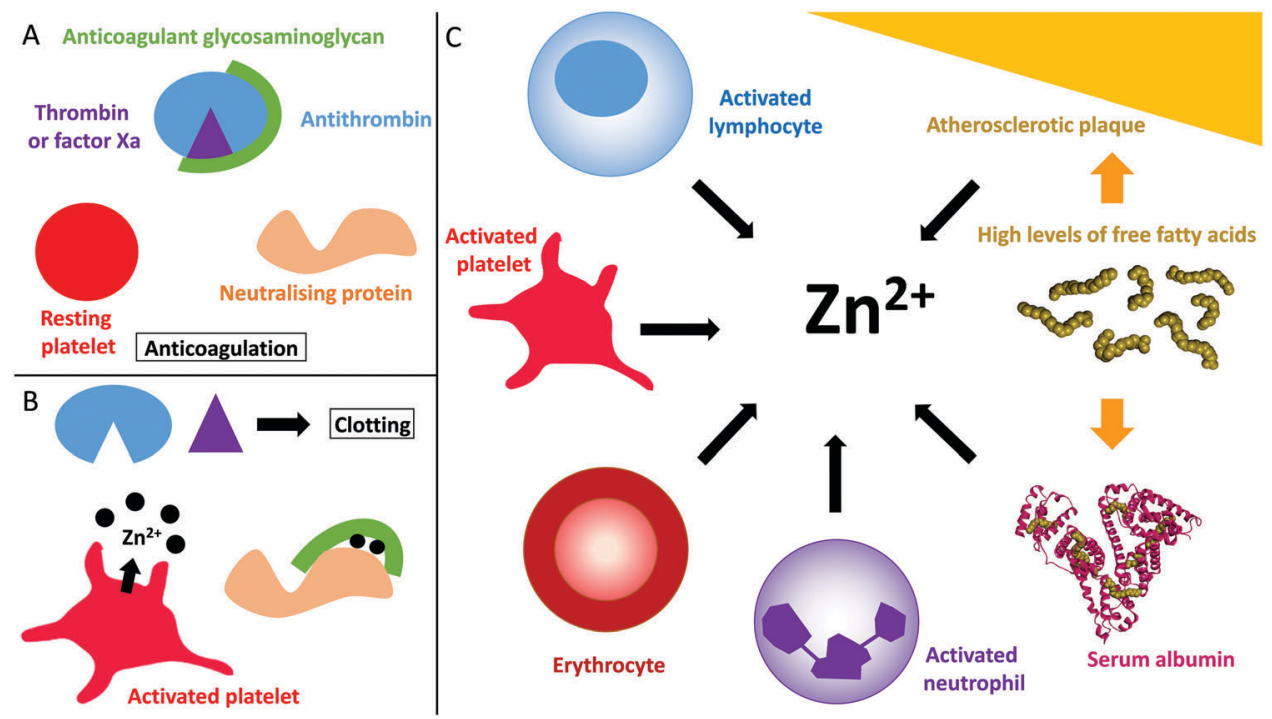

Fig. 1 Coagulation control by glycosaminoglycans and $\mathrm{Zn}^{2+}$. (A) Anticoagulant glycosaminoglycans bind to antithrombin and enhance its neutralisation of thrombin (and/or factor Xa). (B) When platelets become activated, the $\mathrm{Zn}^{2+}$ released from the $\alpha$-granules of platelets bind to the GAG neutralising proteins, increasing their affinity for GAGs and allowing them to neutralise them. Once neutralised, the GAG cannot promote the inhibition of thrombin and clotting occurs. (C) Sources of $\mathrm{Zn}^{2+}$ in plasma. During coagulation, $\mathrm{Zn}^{2+}$ is released by activated platelets. However, erythrocytes, lymphocytes and neutrophils contain $\mathrm{Zn}^{2+}$ which may be released under certain conditions. In some disease states, elevated levels of free fatty acids may also influence available $\mathrm{Zn}^{2+}$ levels through release from serum albumin. Atherosclerotic plaques contain up to six time more $\mathrm{Zn}^{2+}$ than healthy tissue and could potentially release $\mathrm{Zn}^{2+}$ when they rupture. The structure of human serum albumin (with stearate bound) was taken from PDB $1 \mathrm{E} 7 \mathrm{I} .{ }^{109}$ 
upon haemostasis. When looking at specific interactions, $\mathrm{Zn}^{2+}$ has been marked as an initiator of the contact activation pathway of coagulation through enhancing the interactions of contact proteins with polyanionic surfaces and their assembly on endothelial cells and platelets. ${ }^{13} \mathrm{Zn}^{2+}$ enhances platelet aggregation and activation by increasing internal platelet signalling and external binding of platelets to their ligands. ${ }^{13}$ It also enhances fibrin formation while also attenuating thrombin activity. ${ }^{13}$ Simultaneously, $\mathrm{Zn}^{2+}$ is also a regulator of the anticoagulant and fibrinolytic pathways. It can inhibit platelet activation by increasing HMWK and factor XII competition with thrombin to bind GPIb on platelet surface. $\mathrm{Zn}^{2+}$ also attenuates FXa generation by FVIIa, both increases and reduces fibrinolysis and modulates the activities of protein $\mathrm{C}$, protein $\mathrm{S}$ and heparin-mediated anticoagulant pathways and the pro- and anti-coagulation activities of HRG. ${ }^{13}$

Many of the studies examining the impact of $\mathrm{Zn}^{2+}$ on coagulation have utilised purified protein systems where zincbuffering or binding molecules normally found in plasma are absent. Therefore, it is not clear in some cases whether the labile $\mathrm{Zn}^{2+}$ concentrations used are physiologically (or pathophysiologically) attainable. With the involvement of $\mathrm{Zn}^{2+}$ in so many aspects of the clot process, it is difficult to tease out in which $\mathrm{Zn}^{2+}$ may be most involved. Dietary $\mathrm{Zn}^{2+}$ has been shown to exert a pronounced effect on platelet aggregation in humans and rats. ${ }^{16-18}$ Several studies have also investigated correlations between $\mathrm{Zn}^{2+}$ concentrations and clot formation and lysis. Generally, $\mathrm{Zn}^{2+}$ enhances clotting but reduces lysis - specific effects include an increase in fibrin diameter and clot porosity and reductions in clot stiffness. ${ }^{36,43}$ Yet, those studies were realised after dialysing the plasma and adding back $\mathrm{Zn}^{2+}$, a process which may have altered the concentration of certain (likely smaller) molecules that influence clotting.

\section{$\mathrm{Zn}^{2+}$ binding by anticoagulant GAGs}

HS, DS and heparin are highly negatively-charged; thus their binding to other proteins mainly occurs through electrostatic interactions. ${ }^{44}$ This type of interaction will increase with the degree of sulfation of the GAGs. HS is generally less sulfated than heparin but more so than DS. Metal ions are important binding partners of GAGs and, in plasma, both $\mathrm{Ca}^{2+}$ and $\mathrm{Zn}^{2+}$ have been shown to coordinate to them. ${ }^{21}$ Seo, Schenauer and Leary revealed that the binding of metal ions to a heparin octasaccharide, including $\mathrm{Ca}^{2+}, \mathrm{Mn}^{2+}, \mathrm{Co}^{2+}, \mathrm{Fe}^{2+}$ and $\mathrm{Ni}^{2+}$, triggers conformational changes that have the potential to affect their interactions with their ligands. ${ }^{45}$ The effect of $\mathrm{Zn}^{2+}$ was not examined in their study but is likely to mimic the effects of these other metal ions. As both $\mathrm{Ca}^{2+}$ and $\mathrm{Zn}^{2+}$ are released from platelets during coagulation and participate in the regulation of coagulation, this is of particular interest as it is likely that this mechanism alters the anticoagulant activities of heparin and HS following platelet activation. ${ }^{21} \mathrm{UFH}$ has been shown to bind $\mathrm{Zn}^{2+}$ via two different mechanisms: the first represents a high-affinity form of binding (the equilibrium constant is $976 \mathrm{M}^{-1}$ ) whilst the second is a low-affinity form of binding that only occurs at high $\mathrm{Zn}^{2+}$ concentrations (the equilibrium constant is $241 \mathrm{M}^{-1}$ ). ${ }^{46}$ Both binding events are entropy driven and both involve sulfated side chains on the GAGs. The exact stoichiometry of these binding events has not yet been precisely defined but it is assumed that the first mode of binding involves one zinc ion binding per disaccharide and that the second mode intervenes only after saturation is reached for the first one. ${ }^{46}$ GAGs interact with basic amino acids on proteins, generally lysine and arginine side-chains that are not normally affected by the presence of cations. ${ }^{47}$ Those cations however often bind to exposed histidines, which are positively charged, and this binding may then facilitate the binding of the protein to GAGs by reducing the electrostatic repulsion between the two of them. ${ }^{47}$ As $\mathrm{Zn}^{2+}$ is released at the beginning of the coagulation process, its effect on GAG neutralisation reduces anticoagulation and promotes clotting.

\section{Impact of $\mathrm{Zn}^{2+}$ on protein-GAG interactions}

Numerous proteins in plasma have the ability to neutralise anticoagulant GAGs, as reviewed previously. ${ }^{10}$ Among them, three are known to bind $\mathrm{Zn}^{2+}$ : $\mathrm{HRG}^{28}{ }^{28} \mathrm{HMWK}^{29}$ and fibrinogen. ${ }^{27}$ However, the $\mathrm{Zn}^{2+}$ binding properties of all GAG-neutralising proteins have not been examined and there are probably more that possess this ability. This ability to bind $\mathrm{Zn}^{2+}$ is important as $\mathrm{Zn}^{2+}$ has the potential to influence GAG binding and neutralisation by those proteins (Fig. 1). HRG, HMWK and fibrinogen are stored in platelet $\alpha$-granules alongside $\mathrm{Zn}^{2+}$ and are therefore released together during coagulation. All three proteins are synthesised in the liver and, in addition to being stored in platelets, they are present at high nanomolar to low micromolar concentrations in plasma $\left(1.3-2.0 \mu \mathrm{M}\right.$ for $\mathrm{HRG},{ }^{48,49} 1-2 \mu \mathrm{M}$ for $\mathrm{HMWK}^{50}$ and $12-24 \mu \mathrm{M}$ for fibrinogen). ${ }^{51}$ Their specific roles in coagulation are diverse. Fibrinogen plays a prominent role as when it is cleaved, it polymerises to form fibrin clots. ${ }^{52}$ HRG plays a regulatory role by inhibiting fibrinolysis in addition to being incorporated in blood clots, ${ }^{53}$ while HMWK is a key activator of the contact activation pathway of the coagulation cascade. ${ }^{54}$ Thus all three proteins are in contact with endothelial GAGs and are likely to be important for GAGs neutralisation during coagulation. This section will examine the $\mathrm{Zn}^{2+}$ and GAG binding properties of these three proteins and how $\mathrm{Zn}^{2+}$ can influence GAG neutralisation.

\section{Histidine-rich glycoprotein (HRG)}

HRG is a single chain protein composed of several structural domains that include a histidine-rich region (HRR). This region is important in both proteins, as neutrally-charged histidine residues bind $\mathrm{Zn}^{2+}$ via their imidazole side chains. ${ }^{28,48}$ HRG also contains two cystatin-like domains at its N-terminus (N1 and N2) and possesses a C-terminal domain, whilst its histidine-rich region is flanked by two proline-rich regions (Fig. 2). ${ }^{55}$ The structure of HRG has not yet been fully resolved. A crystal structure of the N2 domain has been reported (PDB: $4 \mathrm{CCV}),{ }^{56}$ 


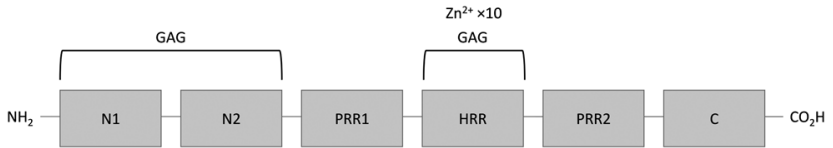

Fig. 2 Structure of histidine-rich glycoprotein. N1 and N2 are N-terminal domain 1 and 2, they have a GAG binding activity; PRR1 and PRR2 are proline-rich regions; HRR is the histidine rich region that binds $\mathrm{Zn}^{2+}$ and GAG: $C$ is the $C$-terminal domain.

but structural information relating to the other domains (including the $\mathrm{Zn}^{2+}$-binding HRR) is lacking. Nevertheless, Human HRG has been demonstrated to bind up to $10 \mathrm{Zn}^{2+}$ ions with an average $K_{\mathrm{d}}$ of $6.13 \mu \mathrm{M} .^{48,57}$ Current evidences suggest that there are no clearly defined preferential binding sites for $\mathrm{Zn}^{2+}$ on HRG. ${ }^{58}$ When the net charge of HRG becomes positive, either through a change in protonation of the histidine residues (through a change in $\mathrm{pH}$ ) or through binding of those residues to metal cations, the conformation of the molecule changes, influencing its affinity for binding its ligands. ${ }^{19,48,58-62}$

HRG binds heparin with a $K_{\mathrm{d}}$ of $32.9 \mathrm{nM}$ in the absence of $\mathrm{Zn}^{2+}$ and $5.1 \mathrm{nM}$ in the presence of $1 \mu \mathrm{M} \mathrm{Zn}{ }^{2+} .{ }^{57}$ Isothermal titration calorimetry studies have shown that there are two different modes of heparin binding, which are thought to occur at different binding sites. ${ }^{57}$ The first mode is $\mathrm{Zn}^{2+}$-dependent and thus most likely involves binding at the HRR. ${ }^{57,63} \mathrm{As} \mathrm{Zn}^{2+}$ only influences the binding of long chain heparins, ${ }^{57}$ this first binding site only involves long chain heparins ( $\geq 10 \mathrm{kDa}) .{ }^{57,64}$ The second mode of binding is not dependent on chain length and is thought to occur at the N1 and N2 domains, ${ }^{20}$ although the exact location of this site is still unknown. The affinity of the second mode of binding is not directly affected by the presence of $\mathrm{Zn}^{2+}$, but $\mathrm{Zn}^{2+}$ binding to the HRR may induce conformation changes in HRG that would make this site more accessible to heparins. HRG forms mainly $1: 1$ complexes with heparin, but it can form 2:1 complexes with longer chain heparins in the presence of $\mathrm{Zn}^{2+} \cdot{ }^{64} \mathrm{HRG}$ has been shown to neutralise heparin in plasma with this ability (like binding) also dependent on the size of the heparin; with longer-chain heparins having a higher affinity for HRG. ${ }^{65}$ For example, even excess ratio of 500:1 HRG: heparin octasaccharide can neutralise less than half of the ability of heparin to accelerate the inactivation of factor Xa by AT. ${ }^{65} \mathrm{Zn}^{2+}$-Dependent heparin binding by HRG only occurs when $\mathrm{Zn}^{2+}$ is released from activated platelets; otherwise, the metal concentration is too low and heparin preferentially binds the AT-thrombin complex. ${ }^{66}$ HRG can neutralise heparinmediated thrombin inhibition by both AT and HCII, but it is much weaker in neutralising DS-mediated thrombin inhibition by HCII. ${ }^{67-69}$ HRG can also bind and neutralise HS in a $\mathrm{Zn}^{2+}$ dependent-manner. ${ }^{70}$ Thus, HRG is an important anticoagulant GAG neutraliser in plasma and this neutralisation is dependent upon the plasma $\mathrm{Zn}^{2+}$ concentration.

\section{High-molecular weight Kininogen (HMWK)}

HMWK is a single chain protein that consists of 6 domains, one of which, domain 5, contains a HRR (Fig. 3). ${ }^{54}$ Kallikrein cleaves domain 4 of HMWK, releasing bradykinin and another peptide,

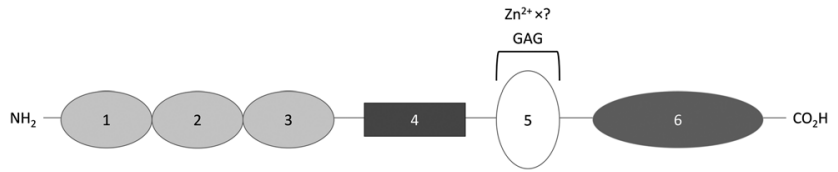

Fig. 3 Structure of high-molecular-weight kininogen. Domains 1, 2 and 3 are cystatin-like domains, with 2 and 3 having a cysteine protease inhibitor activity; domain 4 is bradykinin and another peptide; domain 5 is the surface-binding domain containing the histidine-rich region that binds GAGs and $\mathrm{Zn}^{2+}$; domain 6 is the domain binding prekallikrein and activated coagulation factor XI.

while the rest of the protein forms a two chain HMWK, with the heavy chain being the N-terminal section composed of domain 1, 2 and 3 and the light chain being domain 5 and 6. Both chains are then linked together by a single disulfide bond. ${ }^{54}$ Like HRG, HMWK has not yet been fully crystallised and so the $\mathrm{Zn}^{2+}$ binding domain is also not fully characterised. It is known that $\mathrm{Zn}^{2+}$ binds mainly to histidine residues of the HRR located between the residues Gly440 and Lys458 of domain 5. $\mathrm{Zn}^{2+}$ binding is known to induce a conformational change in this domain. ${ }^{71}$ The affinity and stoichiometry of $\mathrm{Zn}^{2+}$ binding by HMWK have not yet been determined despite its potential to influence the binding of HMWK to its ligands.

Like HRG, HMWK binds heparin in a $\mathrm{Zn}^{2+}$-dependent manner. ${ }^{25}$ The intact form of HMWK binds heparin with higher affinity than the cleaved form of the protein (the $K_{\mathrm{d}}$ values of intact and cleaved forms are $2.1 \mathrm{nM}$ and $14.2 \mathrm{nM}$, respectively). ${ }^{29}$ The presence of $50 \mu \mathrm{M} \mathrm{Zn^{2+ }}$ increases the binding affinity even further $\left(K_{\mathrm{d}}=0.30 \mathrm{nM}\right.$ for intact HMWK). ${ }^{29}$ Heparin binds to the light chain portion of HMWK, at the HRR, in domain 5, which is known to mediate HMWK-binding to negatively-charged surfaces. ${ }^{25,29}$ Within this domain the binding of GAGs occurs at a combination of different sites, some of which are sensitive to $\mathrm{Zn}^{2+} .^{29,47}$ In addition to histidines, this region is rich in lysine residues, which are involved in heparin binding. ${ }^{29,47}$ The heparin binding affinity of HMWK increases when the $\mathrm{pH}$ decreases and the histidine residues become protonated, regardless of the presence of cations. ${ }^{25} \mathrm{UFH}$ and LMWH bind with similar affinity to HMWK in the absence of $\mathrm{Zn}^{2+}$ but the influence of the heparin chain length on the binding affinity in the presence of $\mathrm{Zn}^{2+}$ is not yet known. ${ }^{25}$ HMWK competes with AT, thrombin or the AT-thrombin complex for heparin-binding and can neutralise the anticoagulant effect of heparin in plasma. ${ }^{25}$ However, this binding may not be specific, as HMWK can bind all heparins regardless of whether or not they possess the saccharide sequence used to bind AT with high affinity, and thus several HMWK molecules may be required to fully neutralise one heparin molecule. ${ }^{25}$ Maximal neutralisation has been shown to occur in the presence of $10 \mu \mathrm{M} \mathrm{Zn}^{2+} \cdot{ }^{25}$ In addition, HS proteoglycans located at the cell surface can bind HMWK in a $\mathrm{Zn}^{2+}$-dependent manner but the effect of this binding on the anticoagulant activity of HS has not been investigated directly. ${ }^{50}$ Thus HMWK appears to neutralise anticoagulant GAG in a similar manner to HRG. As HMWK is present in plasma at similar levels to HRG and binds heparin with similar affinity ( $K_{\mathrm{d}}$ in low nanomolar range), 
these proteins may be of equal importance in anticoagulant GAG neutralisation.

\section{Fibrinogen}

Fibrinogen is a homodimer composed of two sets of three different polypeptides chains, $\mathrm{A} \alpha, \mathrm{B} \beta$ and $\gamma$ (Fig. 4). ${ }^{72}$ Most of the protein has been crystallised to some extent, with the exception of the highly variable $\alpha \mathrm{C}$ domain (PDB 3GHG). ${ }^{73}$ Fibrinogen binds $\mathrm{Zn}^{2+}$ at two different regions. The first set of binding sites is located in the D-domains (Fig. 4, insert 1) and has a stoichiometry of six (three ions per D-domain). ${ }^{74}$ The sites predominantly consist of histidine residues located on the $\gamma$ chain, with His- $\gamma 217$ and His- $\gamma 234$ thought to be involved, ${ }^{74}$ however the effect of $\mathrm{Zn}^{2+}$ binding at this region on the conformation of the protein is unknown. Another $\mathrm{Zn}^{2+}$-binding region has been identified in the $\alpha \mathrm{C}$-domain and also involves histidine residues (His- $\alpha 544$ and His- $\alpha 545){ }^{75}$ Binding of $\mathrm{Zn}^{2+}$ to this region is thought to induce a change in the conformation of the protein. ${ }^{75}$ Based on several studies, $\mathrm{Zn}^{2+}$ binding to fibrinogen has an average $K_{\mathrm{d}}$ of $\sim 1-18 \mu \mathrm{M}$, but the individual contributions of the two groups of sites are unknown. ${ }^{27,36,75}$

Two different heparin binding modes have been identified on fibrinogen. The first occurs at a site located on the $\beta$ chain in the $\mathrm{E}$ domain around the $\mathrm{B} \beta 1-57$ region (Fig. 4, insert 2). It has been shown that a synthetic peptide corresponding to this exact region binds heparin with a $K_{\mathrm{d}}$ of $16.5 \mu \mathrm{M},{ }^{76}$ whilst a dimer of the peptide, (Bß1-66) $)_{2}$ exhibits an almost two orders of magnitude higher affinity for heparin ( $K_{\mathrm{d}}$ of $\left.210 \mathrm{nM}\right)$, compared to the monomer. ${ }^{76}$ As this $K_{\mathrm{d}}$ value is close to the $K_{\mathrm{d}}$ of intact fibrinogen (228 $\mathrm{nM}$ ), this suggests that the binding of heparin to fibrinogen occurs predominantly via this binding mode and that the dimeric structure of fibrinogen plays an essential role in this binding. ${ }^{76} \mathrm{~A}$ second heparin-binding mode occurs when $\mathrm{Zn}^{2+}$ binds to the $\alpha \mathrm{C}$ domains of fibrinogen. ${ }^{75}$ Binding of $\mathrm{Zn}^{2+}$ is thought to induce a change in the conformation of the protein promoting heparin-binding to the nearby $\mathrm{E}$ domain. ${ }^{75}$ In presence of $12.5 \mu \mathrm{M} \mathrm{Zn}^{2+}$, the average $K_{\mathrm{d}}$ for heparin binding to fibrinogen is $60 \mathrm{nM}^{75}$ This represents a 4 -fold increase in affinity, contrasting to a lower affinity ( $K_{\mathrm{d}}$ of $539 \mathrm{nM}$ ) for fibrinogen without the $\alpha \mathrm{C}$ domain in the presence of $\mathrm{Zn}^{2+} \cdot{ }^{75}$ The link between heparin chain length and binding affinity in the presence and absence of $\mathrm{Zn}^{2+}$ is not yet known. The binding of fibrinogen to heparin participates in the neutralisation of its anticoagulant activity. The direct study of fibrinogen-mediated GAG neutralisation has been complicated by the fact that thrombin cleaves fibrinogen. However, fibrinogen has been shown to be more effective at neutralising DS than HRG (and platelet factor 4). ${ }^{68}$ This neutralisation occurs at physiological fibrinogen concentrations and is not affected by the size or the degree of sulfation of DS. ${ }^{68}$ The mechanism of neutralisation appears not to occur through direct competition with

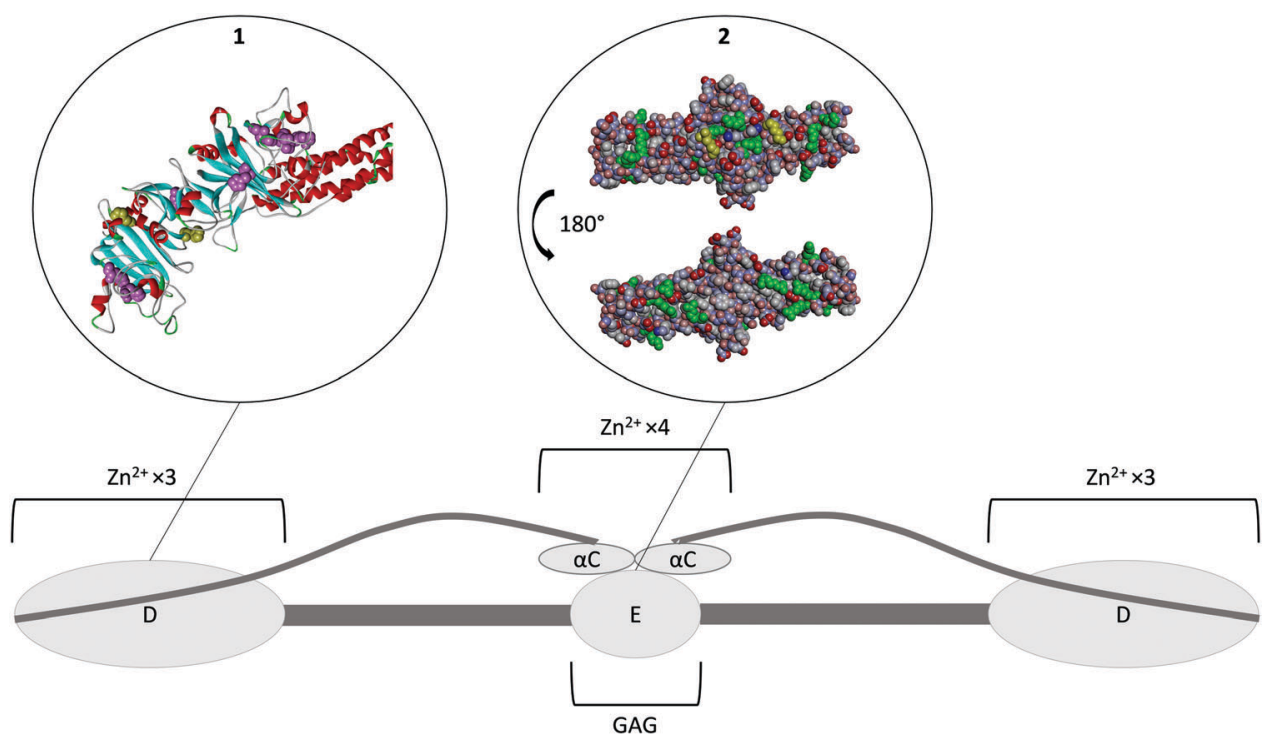

Fig. 4 Structure of fibrinogen. The protein forms hexamer made of three different strands $(A \alpha B \beta \gamma)_{2}$. All of the $\mathrm{N}$-terminals are in the $\mathrm{E}$ domain which is the heparin binding domain. The three strands then coil together until they reach the D domains where the C-terminal of the $\beta$ and $\gamma$ strands are located. This domain is a $\mathrm{Zn}^{2+}$-binding domain. The $\alpha$ strand goes back toward the $\mathrm{E}$ domain where its $\mathrm{C}$-terminal forms the $\alpha \mathrm{C}$ domain, another $\mathrm{Zn}^{2+}$ binding domain. Insert 1. Crystal structure of fibrinogen D domain (one of the $\mathrm{Zn}^{2+}$ binding domain) and part of the coil-coil region (PDB structure $3 G \mathrm{GG}$ ). ${ }^{73}$ The histidine residues which have the potential to be involved in $\mathrm{Zn}^{2+}$ binding are represented in pink with the residues His217 and His234 known to be involved represented in yellow. Most of those residues are hidden beneath the surface of the protein. Insert 2. Crystal structure of fibrinogen $\mathrm{E}$ domain (the heparin binding domain) and part of the coil-coil regions, (PDB structure $3 \mathrm{GHG}$ ). ${ }^{73}$ The positive charges are represented in blue and the negative charges in red. The Lys and Arg residues which usually constitutes the main binding partners of GAGs are represented in green. The first few residues of the $B \beta$ chain are mobile and so they are not visible in the crystal structure, with $\beta 58$ the first residue that can be observed (represented in yellow). This residue is a protruding Lys that is believed to be important for GAG binding. As the GAG binding affinity of fibrinogen is enhanced when the protein is converted into fibrin by cleavage of the $A$ and $B$ peptides, the absence in the crystal structure of the first few residues of the $B \beta$ chain may be the reason for exposure of the $\beta 58$ residue. The $\alpha \mathrm{C}$ domain is attached to the E domain; binding of $\mathrm{Zn}^{2+}$ ions to its His $\alpha 544$ and His $\alpha 545$ is thought to change the conformation of the protein and thus facilitate GAG binding to the E domain. 
the thrombin-HCII complex for DS binding but by controlling the rate of formation of this complex. ${ }^{68}$ In addition, fibrin can also form complexes with heparin, AT and thrombin to reduce thrombin inhibition by AT in a $\mathrm{Zn}^{2+}$-dependent manner. ${ }^{52,77}$ Thus, fibrinogen is an important anticoagulant GAG neutraliser, with the plasma concentration of fibrinogen being linked to heparin resistance in patients. ${ }^{78}$ The sensitivity of fibrinogen toward plasma $\mathrm{Zn}^{2+}$ levels relative to HRG and HMWK is not yet known.

\section{Other anticoagulant GAG neutralising proteins}

$\mathrm{Zn}^{2+}$ can also potentially affect the neutralisation of anticoagulant GAGs through, fibronectin, fibroblast growth factors (FGF), FGF-1 and FGF-7 and activated coagulation factor VII (FVIIa). ${ }^{30,79,80}$ Fibronectin can be found as the alternative spliced forms of cellular or plasma fibronectin. Plasma fibronectin is present in plasma at a concentration of 300-600 $\mathrm{nM}$ and is also stored in platelet $\alpha$-granules and released during coagulation. ${ }^{81}$ Cellular fibronectin is synthesised by endothelial cells and can be released into plasma during wound healing. ${ }^{82} \mathrm{Zn}^{2+}$ binding by fibronectin has not yet been fully characterised, however several regions have been shown to bind $\mathrm{Zn}^{2+}$ in vitro. These include the collagen/gelatin binding domain (binding to which has been shown to elicit a conformational change in this region), ${ }^{30,83,84}$ the cell binding domain ${ }^{30}$ and the alternatively spliced type III connecting segment (IIICS) which is only fully present in cellular fibronectin and a small fraction of plasma fibronectin. ${ }^{85}$ It is still unclear whether plasma fibronectin binds $\mathrm{Zn}^{2+}$ physiologically or whether this only occurs with cellular fibronectin. ${ }^{85,86}$ Considering that $\mathrm{Zn}^{2+}$ induces a conformational change in the protein and may thus influence GAG binding, this is an important question to answer. Fibronectin possess 5-6 ionic GAG binding sites. ${ }^{26,81}$ The first binding site (often termed Hep1) is found in the N-terminal region. As $\mathrm{Zn}^{2+}$ binding to the neighbouring gleatin-binding region induces a conformation change in the protein, it is probable that this could impact on GAG binding in Hep1. ${ }^{83}$ The second GAG binding region (Hep2) has two distinct GAG binding sites and constitutes the high affinity GAG binding region. ${ }^{87}$ As the region is flanked by two $\mathrm{Zn}^{2+}$-binding regions, the cell-binding region and the IIICS, $\mathrm{Zn}^{2+}$ binding may also impact on GAG binding at this site. The global $K_{\mathrm{d}}$ of heparin binding to fibronectin is $0.9 \mu \mathrm{M}$ for a 18-20 saccharide heparin (molecular weight $6000 \mathrm{Da}$ ). ${ }^{87}$ The affinity for UFH is not yet known. Fibronectin does interfere with AT binding to immobilised heparin as a function of heparin concentration. However AT is only completely displaced from heparin at fibronectin/AT ratios higher than are found physiologically. ${ }^{81}$ Fibronectin also binds HS and DS but its effect on their neutralisation is not known. ${ }^{88,89}$ Thus plasma $\mathrm{Zn}^{2+}$ levels have (at least in theory) the potential to influence GAG binding and neutralisation by fibronectin. This means that fibronectin has the potential to strongly react with the $\mathrm{Zn}^{2+}$ released during coagulation and to be major GAG-neutralisers during this time.

Fibroblast growth factors are present at very low concentrations in plasma ( $c$. 28-48 pM for FGF-1 and 643 pM for FGF-7), ${ }^{90,91}$ nevertheless they are normally attached to GAGs of the endothelial surface layer and depend on this binding to exert their functions (including oligomerisation, binding to their cognate receptors and transport between cells). ${ }^{92}$ They are therefore important binding partners for GAGs. FGF-1 and FGF-7 bind UFH with $K_{\mathrm{d}}$ values of $29 \mathrm{nM}$ and $140 \mathrm{nM}$, respectively. ${ }^{93}$ DS also interacts with FGF-7 and FGF-1 but with lower affinity than heparin and HS. FGF-7 and to a lesser extent FGF-1 have been shown to neutralise UFH. ${ }^{94}$ Unlike with HRG, HMWK and fibrinogen, the affinity of these interactions are reduced by the presence of metal ions $\left(\mathrm{Na}^{+}, \mathrm{K}^{+}, \mathrm{Ca}^{2+}, \mathrm{Cu}^{2+}\right.$ and $\left.\mathrm{Zn}^{2+}\right) \cdot{ }^{93}$ However, it is unknown whether metal ion binding influences the neutralisation of the GAG. It is possible that binding of metal ions by these FGFs is a mechanism to facilitate their release from the endothelium when the plasma concentrations of those ions are elevated. Nevertheless, FGF-1 and FGF-7 are unlikely to be important GAG neutralisers in vivo due to their low plasma levels.

FVIIa is a coagulatory protein involved in the contact activation pathway. ${ }^{79,80}$ It binds UFH with a $K_{\mathrm{d}}$ value of $3.38 \mu \mathrm{M}$ in a $\mathrm{Ca}^{2+}$-dependent manner. ${ }^{95}$ FVIIa possesses two $\mathrm{Zn}^{2+}$ binding sites but it is not yet known if binding of $\mathrm{Zn}^{2+}$ plays any role in heparin binding. ${ }^{96}$ FVIIa can neutralise both UFH and LMWH, but its effects on HS and DS have not yet been studied. However, like FGF-1 and FGF-7, FVIIa is only present at a low concentrations in plasma $(\mathrm{ca} .16 \mathrm{nM})^{97}$ and therefore it is not likely to be as relevant in anticoagulant GAG neutralisation as the proteins listed above. Nevertheless, the interaction of $\mathrm{Zn}^{2+}$ with HRG, HMWK and fibrinogen shows that $\mathrm{Zn}^{2+}$ is an important regulator of GAG binding and neutralisation by plasma protein and it is therefore important to investigate whether $\mathrm{Zn}^{2+}$ has the same effect on other GAG neutralising proteins.

\section{Clinical significance of $\mathrm{Zn}^{2+}$-induced GAG neutralisation}

In addition to being released during injury by epithelial cells and platelets, plasma $\mathrm{Zn}^{2+}$ levels are also increased in certain disease states (Fig. 1). Indeed, atherosclerotic plaques are also known to contain up to six-times more $\mathrm{Zn}^{2+}$ than healthy tissue. ${ }^{98}$ However, only total $\mathrm{Zn}^{2+}$ concentration has been measured and so the concentration of labile $\mathrm{Zn}^{2+}$ is not clear. The increase in $\mathrm{Zn}^{2+}$ concentration in atherosclerotic plaques correlates with an increase in $\mathrm{Ca}^{2+}$ concentration. ${ }^{98}$ In addition, both metal ions are present at high levels in areas of plaque mineralisation. ${ }^{99}$ This may signify that the accumulation in both metals occurs through a common mechanism that has not yet been identified. Accumulated $\mathrm{Zn}^{2+}$ could be released into the blood during plaque rupture, thus participating in the pro-thrombotic nature of these events.

The concentration of available $\mathrm{Zn}^{2+}$ is also directly influenced by the plasma free fatty acid (FFA) levels. Serum albumin is the main plasma carrier for both $\mathrm{Zn}^{2+}$ and FFAs. ${ }^{57,100}$ When a FFA molecule binds at a high affinity binding site (called the FA2 site) adjacent to the main $\mathrm{Zn}^{2+}$ binding site, an allosteric interaction leading to perturbation of the $\mathrm{Zn}^{2+}$ binding site occurs. In healthy individuals around $75 \%$ of total plasma $\mathrm{Zn}^{2+}$ 
(around $15 \mu \mathrm{M}$ ) is bound to serum albumin and so this

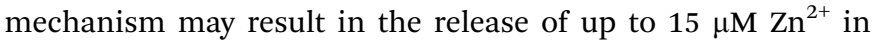
plasma in individuals with elevated FFA levels (when those levels are elevated enough to completely prevent $\mathrm{Zn}^{2+}$ binding by serum albumin). In certain conditions, the concentration of FFA can increase by up to six times: in diabetes FFA concentrations have been reported to be $0.62-0.82 \mathrm{mM}$ in men and 0.82-0.98 $\mathrm{mM}$ in women (compared to controls of $0.59-0.68 \mathrm{mM}$ for men and $0.74-0.83 \mathrm{mM}$ for women). ${ }^{101}$ In non-alcoholic fatty liver disease, the corresponding concentrations are $0.12-3.4 \mathrm{mM}$ (compared to controls of $0.11-0.9 \mathrm{mM}) .{ }^{102}$ In obesity, FFA concentrations are $0.56-1.15 \mathrm{mM}$ (compared to controls of 0.28-0.89 mM). ${ }^{103}$ Elevated FFA levels are also associated with some cancers; in malignant lymphoma FFA concentrations were found to be $0.55-1.8 \mathrm{mM}$ (no controls); ${ }^{104}$ All of these conditions are associated with a higher incidence of developing thrombotic complications. ${ }^{105,106}$ In addition, under hyperglycemic conditions, serum albumin can undergo non-enzymatic glycation reactions which can disrupt the protein conformation and also directly affect its main $\mathrm{Zn}^{2+}$-binding site. ${ }^{107}$ This is another mechanism by which diabetic state can affect $\mathrm{Zn}^{2+}$ transport and speciation.

Another condition that may be associated with altered plasma $\mathrm{Zn}^{2+}$ homeostasis is analbuminemia (albumin deficiency), which is defined as having a plasma albumin level of $<1 \mathrm{~g} \mathrm{~L}^{-1}$. In total, 78 cases have been reported in the analbuminemia register (www.albumin.org) and the prevalence of the disease is estimated to be less than 1 in 1 million. ${ }^{108}$ Individuals with analbuminemia have been reported to have elevated levels of other plasma proteins, including coagulation factors, as a compensatory mechanism. ${ }^{108}$ It is thought that those proteins take up most of the functions of albumin and therefore it is unclear if $\mathrm{Zn}^{2+}$ transport in plasma is affected or not. However, it has been shown that $\mathrm{Ca}^{2+}$ and $\mathrm{Fe}^{2+}$ have an altered proteinbinding profile in these individuals. ${ }^{108}$ The transport of FFA is taken up by apolipoprotein B-100 and so FFA levels are close to normal (but dyslipidaemia is present). ${ }^{108}$ Follow-up studies of patients with analbuminemia have been limited, which limits the report of complications. Nevertheless, such follow-up studies have included reports of atherosclerosis and hypercoagulability in these individuals, ${ }^{108}$ but it is not clear if this may be due to alterations in plasma $\mathrm{Zn}^{2+}$ level/speciation or changes in plasma coagulatory protein levels.

The impact of $\mathrm{Zn}^{2+}$ on anticoagulant GAG-neutralisation is useful to consider, specifically as this process impacts on thrombin activation, an event that directly affects both platelet aggregation (through binding to cell surface receptors) and fibrin clot formation (through cleavage of fibrinogen). Indeed, by enhancing the neutralisation of the GAG present in the endothelium surface layer, $\mathrm{Zn}^{2+}$ induces a change in the natural anticoagulant properties of the endothelium. ${ }^{10}$ When coagulation is needed, this participates in the promotion of clotting. However, if $\mathrm{Zn}^{2+}$ speciation is chronically altered, such as is likely in certain diseases states (atherosclerosis, diabetes, obesity and cancer), then this could affect anticoagulant processes in the endothelium resulting in a pro- or hyper-thrombotic state through enhanced GAG neutralistaion. ${ }^{10}$ This phenomenon could also directly affect the efficiency of heparin-based treatments, which are widely used during surgeries and to manage thrombotic complications. ${ }^{10}$ In order to confirm this, it would be interesting to measure plasma $\mathrm{Zn}^{2+}$ levels in patients undergoing heparin treatment and to compare it to their response to this treatment. If such a relationship is confirmed then an option may be to control $\mathrm{Zn}^{2+}$ levels in those patients rather than to switch to another anticoagulant treatment whose efficiency could also be potentially affected by $\mathrm{Zn}^{2+}$.

\section{Conclusion}

$\mathrm{Zn}^{2+}$ plays a major role in the regulation of coagulation that is only starting to be understood. Because of this role, $\mathrm{Zn}^{2+}$ homeostasis in platelets and its speciation in plasma are especially relevant to the understanding and treatment of blood diseases. In particular, they can affect GAG binding and neutralisation by the platelet-stored proteins HRG, HMWK and fibrinogen. This mechanism is relevant to healthy coagulation processes through the natural anticoagulation properties of the endothelium, but also in anti-thrombotic treatments. Indeed, it may partly explain the observed variability in dose response to heparins and heparin-based drugs. This implies that free plasma $\mathrm{Zn}^{2+}$ levels need to be monitored in individuals with coagulatory disorders or at-risk of thrombotic events. The control of free plasma $\mathrm{Zn}^{2+}$ levels may also be a treatment lead for individuals suffering from high levels of plasma FFA who are at high risk of thrombotic disorders.

\section{Abbreviations}

AT

DS

FGF

FVIIa

GAG

HCII

HMWK

HRG

HRR

HS

IIICS

LMWH

UFH
Antithrombin

Dermatan sulfate

Fibroblast growth factor

Activated coagulation factor VII

Glycosaminoglycan

Heparin cofactor II

High-molecular weight kininogen

Histidine-rich glycoprotein

Histidine-rich region

Heparan sulfate

Type III connecting segment of fibronectin Low molecular weight heparin Unfractionated heparin

\section{Conflicts of interest}

There are no conflicts to declare.

\section{Acknowledgements}

This work was supported by the British Heart Foundation (grant codes: PG/15/9/31270 and FS/15/42/31556). SJP is supported by a Royal Society of Edinburgh Biomedical Fellowship. 


\section{References}

1 E. M. Muñoz and R. J. Linhardt, Heparin-binding domains in vascular biology, Arterioscler., Thromb., Vasc. Biol., 2004, 24, 1549-1557.

2 N. W. Shworak and T. Kobayashi, A. d. Agostini and N. C. Smits, Anticoagulant heparan sulfate to not clot--or not?, Prog. Mol. Biol. Transl. Sci., 2010, 93, 153-178.

3 D. M. Tollefsen, Vascular dermatan sulfate and heparin cofactor II, Prog. Mol. Biol. Transl. Sci., 2010, 93, 351-372.

4 J. A. Marcum, J. B. McKenney, S. J. Galli, R. W. Jackman and R. D. Rosenberg, Anticoagulantly active heparin-like molecules from mast cell-deficient mice, Am. J. Physiol.: Heart Circ. Physiol., 1986, 250, H879-H888.

$5 \mathrm{H}$. Engelberg and A. Dudley, Plasma heparin levels in normal man, Circulation, 1961, 23, 578-581.

6 J. L. Zehnder and S. J. Galli, Mast-cell heparin demystified, Nature, 1999, 400, 714-715.

7 E. Forsberg, G. Pejler, M. Ringvall, C. Lunderius, B. Tomasini-Johansson, M. Kusche-Gullberg, I. Eriksson, J. Ledin, L. Hellman and L. Kjellen, Abnormal mast cells in mice deficient in a heparin-synthesizing enzyme, Nature, 1999, 400, 773-776.

8 D. E. Humphries, G. W. Wong, D. S. Friend, M. F. Gurish, W.-T. Qiu, C. Huang, A. H. Sharpe and R. L. Stevens, Heparin is essential for the storage of specific granule proteases inmast cells, Nature, 1999, 400, 769-772.

9 Venous thromboembolic diseases: diagnosis, management and thrombophilia testing, NICE Clinical guideline (CG144), https://www.nice.org.uk/guidance/cg144, (accessed November 23, 2017).

10 A. I. S. Sobczak, S. J. Pitt and A. J. Stewart, Glycosaminoglycan Neutralization in Coagulation Control, Arterioscler., Thromb., Vasc. Biol., 2018, 38, 1258-1270.

11 W. Li, D. J. Johnson, C. T. Esmon and J. A. Huntington, Structure of the antithrombin-thrombin-heparin ternary complex reveals the antithrombotic mechanism of heparin, Nat. Struct. Mol. Biol., 2004, 11, 857-862.

12 M. Pai and M. A. Crowther, in Handbook of experimental pharmacology volume 207: Heparin - a century of progress, ed. R. Lever, B. Mulloy and C. P. Page, Springer, Berlin, 2012, pp. 265-277.

13 T. T. Vu, J. C. Fredenburgh and J. I. Weitz, Zinc, an important cofactor in haemostasis and thrombosis, Thomb. Haemostasis, 2013, 109, 421-430.

$14 \mathrm{~K}$. Nishida and S. Yamasaki, in Zinc signals in cellular functions and disorders, ed. T. Fukada and T. Kambe, Springer, Japan, 2014, ch. 5, pp. 89-109.

15 B. L. Vallee and K. H. Falchuk, The biochemical basis of zinc physiology, Physiol. Rev., 1993, 73, 79-118.

16 P. R. Gordon, C. W. Woodruff, H. L. Anderson and B. L. O’Dell, Effect of acute zinc deprivation on plasma zinc and platelet aggregation in adult males, Am. J. Clin. Nutr., 1982, 35, 113-119.

17 M. P. Emery, J. D. Browning and B. L. O'Dell, Impaired hemostasis and platelet function in rats fed low zinc diets based on egg white protein, J. Nutr., 1990, 120, 1062-1067.
18 M. P. Emery and B. L. O'Dell, Low zinc status in rats impairs calcium uptake and aggregation of platelets simulate by fluoride, Proc. Soc. Exp. Biol. Med., 1993, 203, 480-484.

19 N. N. Gorgani, C. R. Parish, S. B. E. Smith and J. G. Altin, differential binding of histidine-rich glycoprotein (HRG) to human IgG subclasses and IgG molecules containing k and 1 light chains, J. Biol. Chem., 1999, 274, 29633-29640.

20 A. L. Jones, M. D. Hulett and C. R. Parish, Histidine-rich glycoprotein binds to cell-surface heparan sulfate via its $\mathrm{N}$-terminal domain following $\mathrm{Zn}^{2+}$ chelation, J. Biol. Chem., 2004, 279, 30114-30122.

21 R. Gorodetsky, X. Mou, A. Blankenfeld and G. Marx, Platelet multielemental composition, lability, and subcellular localization, Am. J. Hematol., 1993, 42, 278-283.

22 M. H. Fukami, H. Holmsen, M. A. Kowalska and S. Niewiarowski, in Hemostasis and Thrombosis: Basic Principles and Clinical Practice, ed. R. W. Colman, J. Hirsh, V. J. Marder, A. W. Clowes and J. N. George, Lippincott Williams \& Wilkins, Philadelphia, 2001, pp. 561-573.

23 S. Raut and P. J. Gaffney, Interaction of heparin with fibrinogen using durface plasmon resonance technology: investigation of heparin binding site on fibrinogen, Thromb. Res., 1996, 15, 503-509.

24 H. R. Lijnen, M. Hoylaerts and D. Collen, Heparin binding properties of human histidine-rich glycoprotein. Mechanism and role in the neutralization of heparin in plasma, J. Biol. Chem., 1983, 258, 3803-3808.

25 I. Bjoerk, S. T. Olson, R. G. Sheffer and J. D. Shore, Binding of heparin to human high molecular weight kininogen, Biochemistry, 1989, 28, 1213-1221.

26 A. Ogamo, A. Nagai and K. Nagasawa, Binding of heparin fractions and other polysulfated polysaccharides to plasma fibronectin: effects of molecular size and degree of sulfation of polysaccharides, Biochim. Biophys. Acta, 1985, 841, 30-41.

27 G. Marx, Zinc binding to fibrinogen and fibrin, Arch. Biochem. Biophys., 1988, 266, 285-288.

28 W. T. Morgan, Human serum histidine-rich glycoprotein. I. Interactions with heme, metal ions and organic ligands, Biochim. Biophys. Acta, 1978, 535, 319-333.

29 Y. Lin, R. A. Pixley and R. W. Colman, Kinetic analysis of the role of zinc in the interaction of domain 5 of highmolecular weight kininogen (HK) with heparin, Biochemistry, 2000, 39, 5104-5110.

30 B. Gmeiner, H. Leibl, G. Zerlauth and C. Seelos, Affinity binding of distinct functional fibronectin domains to immobilized metal chelates, Arch. Biochem. Biophys., 1995, 321, 40-42.

31 C. A. Blindauer, I. Harvey, K. E. Bunyan, A. J. Stewart, D. Sleep, D. J. Harrison, S. Berezenko and P. J. Sadler, Structure, properties, and engineering of the major zinc binding site on human albumin, J. Biol. Chem., 2009, 284, 23116-23124.

32 H. Haase, S. Hebel, G. Engelhardt and L. Rink, The biochemical effects of extracellular $\mathrm{Zn}(2+)$ and other metal ions are severely affected by their speciation in cell culture media, Metallomics, 2015, 7, 102-111. 
33 B. Sarkar, Metal-protein interactions in transport, accumulation and excretion of metals, Biol. Trace Elem. Res., 1989, 21, 137-144.

34 E. Kelly, J. Mathew, J. E. Kohler, A. L. Blass and D. I. Soybel, Redistribution of labile plasma zinc during mild surgical stress in the rat, Transl. Res., 2011, 157, 139-149.

35 F. Mahdi, Z. S. Madar, C. D. Figueroa and A. H. Schmaier, Factor XII interacts with the multiprotein assembly of urokinase plasminogen activator receptor, gC1qR, and cytokeratin 1 on endothelial cell membranes, Blood, 2002, 99, 3585-3596.

36 S. J. Henderson, A. R. Stafford, B. A. Leslie, P. Y. Kim, N. Vaezzadeh, R. Ni, J. C. Fredenburgh and J. I. Weitz, Zinc delays clot lysis by attenuating plasminogen activation and plasmin-mediated fibrin degradation, Thromb. Haemost., 2015, 113, 1278-1288.

37 G. Marx, G. Korner, X. Mou and R. Gorodetsky, Packaging zinc, fibrinogen, and factor XIII in platelet alpha-granules, J. Cell. Physiol., 1993, 156, 437-442.

38 K. A. Taylor and N. Pugh, The contribution of zinc to platelet behaviour during haemostasis and thrombosis, Metallomics, 2016, 8, 144-155.

39 R. C. Whitehouse, A. S. Prasad, P. I. Rabbani and Z. T. Cossack, Zinc in plasma, neutrophils, lymphocytes, and erythrocytes as determined by flameless atomic absorption spectrophotometry, Clin. Chem., 1982, 28, 475-480.

40 G. Michaelsson, K. Ljunghall and B. G. Danielson, Zinc in epidermis and dermis in healthy subjects, Acta Derm.Venereol., 1980, 60, 295-299.

41 H. Sharir, A. Zinger, A. Nevo, I. Sekler and M. Hershfinkel, Zinc released from injured cells is acting via the $\mathrm{Zn} 2+-$ sensing receptor, $\mathrm{ZnR}$, to trigger signaling leading to epithelial repair, J. Biol. Chem., 2010, 285, 26097-26106.

42 S. Tubek, P. Grzanka and I. Tubek, Role of zinc in hemostasis: a review, Biol. Trace Elem. Res., 2008, 121, 1-8.

43 S. J. Henderson, J. Xia, H. Wu, A. R. Stafford, B. A. Leslie, J. C. Fredenburgh, D. A. Weitz and J. I. Weitz, Zinc promotes clot stability by accelerating clot formation and modifying fibrin structure, Thromb. Haemostasis, 2016, 115, 533-542.

44 I. Capila and R. J. Linhardt, Heparin-protein interactions, Angew. Chem., Int. Ed., 2002, 41, 390-412.

45 Y. Seo, M. R. Schenauer and J. A. Leary, Biologically relevant metal-cation binding induces conformational changes in heparin oligosaccharides as measured by ion mobility mass spectrometry, Int. J. Mass Spectrom., 2011, 303, 191-198.

46 N. E. Woodhead, W. F. Long and F. B. Williamson, Binding of zinc ions to heparin. Analysis by equilibrium dialysis suggests the occurrence of two, entropy-driven, processes, Biochem. J., 1986, 237, 281-284.

47 R. A. Pixley, Y. Lin, I. Isordia-Salas and R. W. Colman, Fine mapping of the sequences in domain 5 of high molecular weight kininogen (HK) interacting with heparin and zinc, J. Thromb. Haemost., 2003, 1, 1791-1798.
48 A. L. Jones, M. D. Hulett and C. R. Parish, Histidine-rich glycoprotein: A novel adaptor protein in plasma that modulates the immune, vascular and coagulation systems, Immunol. Cell Biol., 2005, 83, 106-118.

49 J. J. Corrigan, M. A. Jeter, D. Bruck and W. M. Feinberg, Histidine-rich glycoprotein levels in children: the effect of age, Thromb. Res., 1990, 59, 681-686.

50 T. Renné, J. Dedio, G. David and W. Müller-Esterl, High molecular weight kininogen utilizes heparan sulfate proteoglycans for accumulation on endothelial cells, J. Biol. Chem., 2000, 275, 33688-33696.

51 G. A. Tennent, S. O. Brennan, A. J. Stangou, J. O'Grady, P. N. Hawkins and M. B. Pepys, Human plasma firbinogen is synthesized in the liver, Blood, 2007, 109, 1971-1974.

52 P. J. Hogg and C. M. Jackson, Fibrin monomer protects thrombin from inactivation by heparin-antithrombin III: implications for heparin efficacy, Proc. Natl. Acad. Sci. U. S. A., 1989, 86, 3619-3623.

53 I. K. H. Poon, K. K. Patel, D. S. Davis, C. R. Parish and M. D. Hulett, Histidine-rich glycoprotein: the SwissArmy knife of mammalian plasma, Blood, 2011, 117, 2093-2101.

54 J. W. Weisel, C. Nagaswami, J. L. Woodhead, R. A. D. Cadena, J. D. Page and R. W. Colman, The shape of high molecular weight kininogen. Organization into structural domains, changes with activation, and interactions with prekallikrein, as determined by electron microscopy, J. Biol. Chem., 1994, 269, 10100-10106.

55 T. K. D. Foster, S. Yoshitake and E. W. Davie, Amino acid sequence of human histidine-rich glycoproteiq derived from the nucleotide sequence of its cDNA, Biochemistry, 1986, 25, 2220-2225.

56 O. Kassaar, S. A. McMahon, R. Thompson, C. H. Blotting, J. H. Naismith and A. J. Stewart, Crystal structure of histidine-rich glycoprotein N2 domain reveals redox activity at an interdomain disulfide bridge: implications for angiogenic regulation, Blood, 2014, 123, 1948-1955.

57 O. Kassaar, U. Schwarz-Linek, C. A. Blindauer and A. J. Stewart, Plasma free fatty acid levels influence $\mathrm{Zn}^{2+}$-dependent histidine-rich glycoprotein-heparin interactions via an allosteric switch on serum albumin, J. Thromb. Haemostasis, 2015, 13, 101-110.

58 E. M. Martin, F. D. L. Kondrat, A. J. Stewart, J. H. Scrivens, P. J. Sadler and C. A. Blindauer, Native electrospray mass spectrometry approaches to probe the interaction between zinc and an anti-angiogenic peptide from histidine-rich glycoprotein, Sci. Rep., 2018, 8, 8646.

59 S. Mori, R. Shinohata, M. Renbutsu, H. K. Takahashi, Y. I. Fang, K. Yamaoka, M. Okamoto and M. Nishibori, Histidine-rich glycoprotein plus zinc reverses growth inhibition of vascular smooth muscle cells by heparin, Cell Tissue Res., 2003, 312, 353-359.

60 J. L. MacQuarrie, A. R. Stafford, J. W. Yau, B. A. Leslie, T. T. Vu, J. C. Fredenburgh and J. I. Weitz, Histidine-rich glycoprotein binds factor XIIa with high affinity and inhibits contact-initiated coagulation, Blood, 2011, 117, 4134-4141. 
61 D. B. Borza and W. T. Morgan, Histidine-proline-rich glycoprotein as a plasma pH sensor, J. Biol. Chem., 1998, 273, 5493-5499.

62 K. M. Priebatsch, M. Kvansakul, I. K. Poon and M. D. Hulett, Functional Regulation of the Plasma Protein Histidine-Rich Glycoprotein by $\mathrm{Zn}(2+)$ in Settings of Tissue Injury, Biomolecules, 2017, 7, 22.

63 M. Vanwildemeersch, A. K. Olsson, E. Gottfridsson, L. Claesson-Welsh, U. Lindahl and D. Spillmann, The anti-angiogenic His/Pro-rich fragment of histidine-rich glycoprotein binds to endothelial cell heparan sulfate in a $\mathrm{Zn}^{2+}$-dependent manner, J. Biol. Chem., 2006, 281, 10298-10304.

64 M. K. Burch, M. N. Blackburn and W. T. Morgan, Further characterization of the interaction of histidine-rich glycoprotein with heparin: evidence for the binding of two molecules of histidine-rich glycoprotein by high molecular weight heparin and for the involvement of histidine residues in heparin binding, Biochemistry, 1987, 26, 7477-7482.

65 D. Lane, G. Pejler, A. Flynn, E. Thompson and U. Lindahl, Neutralization of heparin-related saccharides by histidinerich glycoprotein and platelet factor-4, J. Biol. Chem., 1986, 261, 3980-3986.

66 B. A. Kluszynski, C. Kim and W. P. Faulk, Zinc as a Cofactor for Heparin Neutralization by Histidine-rich Glycoprotein, J. Biol. Chem., 1997, 272, 13541-13547.

67 D. M. Tollefsen and C. A. Pestka, Modulation of heparin cofactor II activity by histidine-rich glycoprotein and platelet factor 4, J. Clin. Invest., 1985, 75, 496-501.

68 A. Zammit and J. Dawes, Fibrinogen inhibits the heparin cofactor II-mediated antithrombin activity of dermatan sulfate, Blood, 1995, 85, 720-726.

69 G. Cella, G. Boeri, G. Saggiorato, R. Paolini, G. Luzzatto and $\mathrm{V}$. Terribile, Interaction between histidine-rich glycoprotein and platelet factor 4 with dermatan sulfate and low-molecular-weight dermatan sulfate, Angiology, 1992, 43, 59-62.

70 A. L. Jones, M. D. Hulett and C. R. Parish, Histidine-rich glycoprotein binds to cell-surface heparan sulfate via its $\mathrm{N}$-terminaldDomain following $\mathrm{Zn}^{2+}$ chelation, J. Biol. Chem., 2004, 279, 30114-30122.

71 H. Herwald, M. Mörgelin, H. G. Svensson and U. Sjöbring, Zinc-dependent conformational changes in domain D5 of high molecular mass kininogen modulate contact activation, Eur. J. Biochem., 2001, 268, 396-404.

72 J. M. Kollman, L. Pandi, M. R. Sawaya, M. Riley and R. F. Doolittle, Crystal structure of human fibrinogen, Biochemistry, 2009, 48, 3877-3886.

73 R. F. Doolittle, Z. Yang and I. Mochalkin, Crystal structure studies on fibrinogen and fibrin, Ann. N. Y. Acad. Sci., 2001, 936, 31-43.

74 M. F. Scully and V. V. Kakkar, Binding of fibrinogen fragment $\mathrm{D}$ to chelated zinc: localization of a possible binding site, Thromb. Res., 1983, 30, 297-300.

75 J. C. Fredenburgh, B. A. Leslie, A. R. Stafford, T. Lim, H. H. Chan and J. I. Weitz, $\mathrm{Zn}^{2+}$ mediates high affinity binding of heparin to the aC domain of fibrinogen, J. Biol. Chem., 2013, 288, 29394-29402.

76 S. Yakovlev, S. Gorlatov, K. Ingham and L. Medved, Interaction of fibrin(ogen) with heparin: further characterization and localization of the heparin-binding site, Biochemistry, 2003, 42, 7709-7716.

77 H. H. Chan, B. A. Leslie, A. R. Stafford, R. S. Roberts, N. N. Al-Aswad, J. C. Fredenburgh and J. I. Weitz, By increasing the affinity of heparin for fibrin, $\mathrm{Zn}^{2+}$ promotes the formation of a ternary heparin-thrombin-fibrin complex that protects thrombin from inhibition by antithrombin, Biochemistry, 2012, 51, 7964-7973.

78 T. Holger-Madsen and M. Schioler, Heparin resitsance (measured by the heparin thrombin time) and plasma fibrinogen in various dieases, Acta Haematol., 1962, 27, 294-305.

79 L. Poller, Factor VII and heparin in thrombosis, J. Clin. Pathol., 1959, 12, 331-334.

80 G. Young, K. E. Yonekawa, P. A. Nakagawa, R. C. Blain, A. E. Lovejoy and D. J. Nugent, Recombinant activated factor VII effectively reverses the anticoagulant effects of heparin, enoxaparin, fondaparinux, argatroban, and bivalirudin ex vivo as measured using thromboelastography, Blood Coagulation Fibrinolysis, 2007, 18, 547-553.

81 Y. Byun, H. A. Jacobs, J. Feijen and S. W. Kim, Effect of fibronectin on the binding of antithrombin III to immobilized heparin, J. Biomed. Mater. Res., 1996, 30, 95-100.

82 W. S. To and K. S. Midwood, Plasma and cellular fibronectin: distinct and independent functions during tissue repair, Fibrog. Tissue Repair, 2011, 4, 21-38.

83 M. Graille, M. Pagano, T. Rose, M. R. Ravaux and H. V. Tilbeurgh, Zinc induces structural reorganization of gelatin binding domain from human fibronectin and affects collagen binding, Structure, 2010, 18, 710-718.

84 S. L. Vidmar, F. Lottspeich, I. Emod, J. M. Imhoff and V. Keil-Dlouha, Collagen-binding domain of human plasma fibronectin contains a latent type-IV collagenase, Eur. J. Biochem., 1991, 201(1), 79-84.

85 J. A. Askari, D. J. Thornton, J. D. Humphries, P. A. Buckley and M. J. Humphries, The alternatively spliced type III connecting segment of fibronectin is a zinc-binding module, Matrix Biol., 2007, 26, 485-493.

86 M. J. Sinosich, M. W. Davey, B. Teisner and J. G. Grudzinskas, Comparative studies of pregnancy associated plasma proteinA and alpha 2-macroglobulin using metal chelate chromatography, Biochem. Int., 1983, 7, 33-42.

87 K. C. Ingham, S. A. Brew and D. H. Atha, Interaction of heparin with fibronectin and isolated fibronectin domains, Biochem. J., 1990, 272, 605-611.

88 G. Schmidt, H. Robenek, B. Harrach, J. Glössl, V. Nolte, H. Hörmann, H. Richter and H. Kresse, Interaction of small dermatan sulfate proteoglycan from fibroblasts with fibronectin, J. Cell Biol., 1987, 104, 1683-1691.

89 S. Tumova, A. Woods and J. R. Couchman, Heparan sulfate chains from glypican and syndecans bind the Hep II domain of fibronectin similarly despite minor structural differences, J. Biol. Chem., 2000, 275, 9410-9417. 
90 S. Kumara, H. Miyagaki, D. Giata, X. Yan, L. Njoh, C. Vesna, M. M. Alvarez-Downing and R. L. Whelan, Plasma levels of Keratinocyte Growth Factor, a proangiogenic protein, are significantly elevated for 3 weeks after minimally invasive colorectal resection (MICR) for cancer, Surg. Endosc., 2012, 26, 2751-2757.

91 S. Wang, Q. Yang, S. Yu, R. Pan, D. Jiang, Y. Liu, H. Hu, W. Sun, X. Hong, H. Xue, W. Qian, D. Wang, L. Zhou, C. Mao and G. Yuan, Fibroblast growth factor 1 levels are elevated in newly diagnosed type 2 diabetes compared to normal glucose tolerance controls, Endocr. J., 2016, 63, 359-365.

92 A. Beenken and M. Mohammadi, The FGF family: biology, pathophysiology and therapy, Nat. Rev. Drug Discovery, 2009, 8, 235-253.

93 R. Xu, A. Ori, T. R. Rudd, K. A. Uniewicz, Y. A. Ahmed, S. E. Guimond, M. A. Skidmore, G. Siligardi, E. A. Yates and D. G. Fernig, Diversification of the structural determinants of fibroblast growth factor-heparin interactions: implications for binding specificity, J. Biol. Chem., 2012, 287, 40061-40073.

94 Y. d. Luo, H. H. Cho and W. L. McKeehan, Biospecific extraction and neutralization of anticoagulant heparin with fibroblast growth factors (FGF), J. Pharm. Sci., 2003, 92, 2117-2127.

95 I. Martínez-Martínez, A. Ordóñez, S. Pedersen, M. E. de la Morena-Barrio, J. Navarro-Fernández, S. R. Kristensen, A. Miñano, J. Padilla, V. Vicente and J. Corral, Heparin affinity of factor VIIa: implications on the physiological inhibition by antithrombin and clearance of recombinant factor VIIa, Thromb. Res., 2011, 127, 154-160.

96 L. C. Petersen, O. H. Olsen, L. S. Nielsen, P. O. Freskgård and E. Persson, Binding of $\mathrm{Zn}^{2+}$ to a $\mathrm{Ca}^{2+}$ loop allosterically attenuates the activity of factor VIIa and reduces its affinity for tissue factor, Protein Sci., 2000, 9, 859-866.

97 B. Blombäck and L. A. Hanson, Plasma proteins, Wiley, Chichester, 1979.

98 N. Stadler, N. Stanley, S. Heeneman, V. Vacata, M. J. Daemen, P. G. Bannon, J. Waltenberger and M. J. Davies, Accumulation of zinc in human atherosclerotic lesions correlates with calcium levels but does not protect against protein oxidation, Arterioscler., Thromb., Vasc. Biol., 2008, 28, 1024-1030.

99 D. Kopriva, A. Kisheev, D. Meena, S. Pelle, M. Karnitsky, A. Lavoie and J. Buttigieg, The Nature of Iron Deposits Differs between Symptomatic and Asymptomatic Carotid Atherosclerotic Plaques, PLoS One, 2015, 10, e0143138.

100 A. J. Stewart, C. A. Blindauer and P. J. Sadler, Plasma fatty acid levels may regulate the $\mathrm{Zn}^{2+}$-dependent activities of histidine-rich glycoprotein, Biochimie, 2009, 91, 1518-1522.

101 M. Carlsson, Y. Wessman, P. Almgren and L. Groop, High levels of nonesterified fatty acids are associated with increased familial risk of cardiovascular disease, Arterioscler., Thromb., Vasc. Biol., 2000, 20, 1588-1594.

102 J. Zhang, Y. Zhao, C. Xu, Y. Hong, H. Lu, J. Wu and Y. Chen, Association between serum free fatty acid levels and nonalcoholic fatty liver disease: a cross-sectional study, Sci. Rep., 2014, 4, 5832.

103 P. Bjorntorp, H. Bergman and E. Varnauskas, Plasma free fatty acid turnover rate in obesity, Acta Med. Scand., 1969, 185, 351-356.

104 J. Nuutinen, H. Minn, J. Bergman, M. Haaparanta, U. Ruotasalainen, H. Laine and J. Knuuti, Uncoupling of fatty acid and glucose metabolism in malignant lymphoma: a PET study, Br. J. Cancer, 1999, 80, 513-518.

105 E. Privateli, P. Bucciarelli, S. M. Pasamonit and I. Martinelli, Risk factors vor venous and arterial thrombosis, J. Blood Transfus., 2011, 9, 120-138.

106 G. C. Connolly and A. A. Khorana, Risk stratification for cancer-associated venous thromboembolism, Best Pract. Res., Clin. Haematol., 2009, 22, 35-47.

107 S. Iqbal, F. A. Qais, M. M. Alam and I. Naseem, Effect of glycation on human serum albumin-zinc interaction: a biophysical study, J. Biol. Inorg. Chem., 2018, 23, 447-458.

108 B. G. Koot, R. Houwen, D. J. Pot and J. Nauta, Congenital analbuminaemia: biochemical and clinical implications. A case report and literature review, Eur. J. Pediatr., 2004, 163, 664-670.

109 A. A. Bhattacharya, T. Grune and S. Curry, Crystallographic analysis reveals common modes of binding of medium and long-chain fatty acids to human serum albumin, J. Mol. Biol., 2000, 303, 721-732. 